$\overline{\text { Original }}$

\title{
Laccase Production and One-electron Oxidation Activity in Wood Degradation by the Soft-rot Deuteromycete Graphium sp.
}

\author{
HIROMI TANAKA*, SHUJI ITAKURA, AND AKIO ENOKI \\ Department of Agricultural Chemistry, Faculty of Agriculture, Kinki \\ University, Nakamachi, Nara 631-8505, Japan
}

Received 7 July 1999/Accepted 17 September 1999

\begin{abstract}
The mechanism of wood degradation by the soft-rot deuteromycete, Graphium sp., was investigated. One-electron oxidation activity, assayed by ethylene generation from 2-keto-4thiomethylbutyric acid (KTBA), and phenol oxidase activity were measured in intact cultures and in Sephadex G-50 fractions from the acetone-precipitated extracellular media, with glucose or wood as the carbon source for the cultures. Both the one-electron oxidation activity and the phenol oxidase activity were higher in wood cultures than in glucose cultures. Most of the phenol oxidase activity in wood cultures appeared to derive from laccase. Most of the ethylene generation from KTBA was attributed to hydroxyl radicals, produced by a lowmolecular-weight substance in the extracellular media. This substance was composed of peptides, carbohydrates, and $\mathrm{Fe}$ (II), and catalyzed redox reactions between $\mathrm{O}_{2}$ and unidentified electron donors, to produce hydroxyl radicals via $\mathrm{H}_{2} \mathrm{O}_{2 \text {. }}$ It is suggested that hydroxyl radicals may produce new phenolic substructures on the lignin polymer, making it susceptible to attack by laccase. Thus, both one-electron oxidation activity and laccase activity are important in wood degradation by Graphium sp.
\end{abstract}

Key words : Soft-rot decay/Graphium sp. /Laccase/One-electron oxidation.

\section{INTRODUCTION}

Graphium sp. is the asexual form of the ascomycete fungus Ceratocystis sp., a well-known blue-stainer of softwood. Graphium sp. has been isolated from imported North American timber such as Douglas fir (Pseudotsuga menziesii Franco) and western hemlock (Tsuga heterophylla Sarg.) that has been treated for the prevention of sap-stain (Kumagai and Tsunoda, 1999). Since these two softwood species account for about $40 \%$ of the total wood supply in Japan, sap-stain treatments are very important for reducing economic losses. Graphium sp. also causes significant weight loss in hardwood and therefore is considered to be a soft-rot fungus (Eslyn et al., 1975; Tanaka et al., 1992). Thus, the control of Graphium

${ }^{*}$ Corresponding author. Tel : +81-742-43-1511, Fax : +81742-43-1551 $\mathrm{sp}$. is of economic importance.

There are three types of fungal wood decay. Whiterot, produced by some basidiomycetes, results from the removal of the cell wall components of wood (Enoki et al., 1988). In contrast, brown-rot, which also is produced by members of the basidiomycetes, results from the preferential degradation of wood polysaccharides (Enoki et al., 1988). Soft-rot is caused by members of the ascomycetes and deuteromycetes (Duncan, 1960; Eslyn et al., 1975; Savory, 1954). The typical soft-rot decay symptoms are cavity formation in the $S_{2}$ layer of wood cell walls, erosion of the luminal surfaces of the cell walls, and penetration by fine hyphae through cell walls (Zabel and Morrell, 1992). During soft-rot decay, the cellulose and hemicellulose in wood are depleted at similar rates; whereas the lignin in wood is depleted much more slowly (Eslyn et al., 1975; Tanaka et al., 1992). However the mechanisms of wood degradation by 
soft-rot fungi are not well understood.

Some deuteromycetes produce a complete system of cellulases and hydrolyze highly-crystalline cellulose to glucose efficiently; however, they cannot degrade the cellulose component in wood, because lignin prevents the cellulase from accessing its substrate and these fungi lack a system for attacking the lignin (Highley, 1973; Tanaka et al., 1985). Since direct contact between the cellulases and the substrate is essential, wood-degrading fungi must possess a precellulolytic system for opening up the complex cell wall structure of wood in order to hydrolyze the cellulose (Bailey et al., 1968). A number of studies have investigated the pre-cellulolytic systems of white-rot and brown-rot fungi.

White-rot fungi degrade the lignin in wood, in preference to the cellulose, only in cultures with high levels of phenol oxidase activity (Tanaka et al., 1985, 1986). In white-rot fungi, at least one phenol-oxidizing enzyme is involved in and/or is essential for the preferential degradation of lignin in wood, in concert with a system that produces hydroxyl radicals (Tanaka et al., 1999b). During brown-rot decay, characterized by the preferential elimination of the polysaccharides in wood, significant amounts of the hydroxyl radical are produced in the wood cell walls (Enoki et al., 1989; Itakura et al., 1994). Hydroxyl radicals can depolymerize crystalline cellulose and destroy the crystalline structure (Kirk et al., 1991; Koenigs, 1974). Hydroxyl radicals also can attack the aromatic rings in lignin, causing a variety of reactions including hydroxylation and ring-opening (Gierer et al., 1992), but they cannot remove the lignin from wood to a significant degree (Chirat and Lachenal, 1997; Enoki et al., 1997). Therefore brown-rot fungi, which lack both phenol oxidase activity and exo-1,4- $\beta$-glucanase activity, remove the polysaccharides in wood in preference to the lignin (Enoki et al., 1988; Highley, 1987).

In order to better understand the mechanism of wood degradation by the soft-rot fungus Graphium sp., we have isolated and identified phenol oxidases from this fungus and determined the agent responsible for the one-electron oxidation in cultures of the fungus.

\section{MATERIALS AND METHODS}

\section{Organism}

The soft-rot deuteromycete, Graphium sp. M-1-9, was isolated from untreated sapwood stakes $(2 \times 2 \times$ $20 \mathrm{~cm}$ ) of Japanese beech (Fagus crenata Blume) and Japanese cedar (Cryptomeria japonica D. Don) (Tanaka and Fuse, 1981 and 1983). Stock cultures of the fungus were maintained on slants of potato sucrose agar.

\section{Culture conditions}

Duncan's medium contained $\mathrm{KH}_{2} \mathrm{PO}_{4}$ (5.0g), $\mathrm{MgSO}_{4} \cdot 7 \mathrm{H}_{2} \mathrm{O}$ (4.0g), $\mathrm{K}_{2} \mathrm{HPO}_{4}(4.0 \mathrm{~g}), \mathrm{NH}_{4} \mathrm{NO}_{3}$ (6.0g), and agar $(20 \mathrm{~g})$, per liter of distilled water. For "glucose cultures", $10 \mathrm{ml}$ of Duncan's medium contained $2 \%$ (w/v) glucose. For "wood particle cultures", particles (about $5 \mathrm{~mm}^{3}, 1.2 \mathrm{~g}$ ) of Japanese beech or Japanese cedar were sterilized and sprinkled evenly over the surface of $10 \mathrm{ml}$ of Duncan's medium containing $0.25 \%(\mathrm{w} / \mathrm{v})$ glucose. For "wood meal cultures", wood meal (10-80 mesh) of Japanese beech (1.2g) replaced the wood particles. The wood particles and wood meal were extracted twice with acetone while being refluxed, and then dried before use. The cultures, in 50-ml Erlenmeyer flasks, were inoculated with a small piece of fungal mat and incubated at 28 ${ }^{\circ} \mathrm{C}$.

\section{Ethylene generation from 2-keto-4-thiomethylbu- tyric acid (KTBA) in cultures}

At the indicated times, KTBA $(3 \mathrm{ml}$ of $10 \mathrm{mM})$ was added to the glucose, wood particle, and wood meal cultures. The cotton plugs of the flasks were replaced with rubber septa and the flasks were purged with $100 \%(\mathrm{v} / \mathrm{v}) \mathrm{O}_{2}$ for $10 \mathrm{~min}$. After $24 \mathrm{~h}$ at $28^{\circ} \mathrm{C}, 1 \mathrm{ml}$ of gas was removed from the head space of each flask, and the ethylene concentration was measured directly by gas chromatography as previously described (Enoki et al., 1989).

\section{Phenol oxidase activity in cultures}

Phenol oxidase activity was assayed spectrophotometrically, using 2,2' -azinobis (3-ethylbenzothiazoline6-sulfonic acid) (ABTS) or guaiacol as the substrate. At the indicated times, $2 \mathrm{ml}$ of $10 \mathrm{mM}$ ABTS or $20 \mathrm{mM}$ guaiacol and $18 \mathrm{ml}$ of $50 \mathrm{mM}$ acetate buffer ( $\mathrm{pH} 4.5$ ) were added to the glucose, wood particle, and wood meal cultures. After shaking for $1 \mathrm{~h}$ at $30^{\circ} \mathrm{C}$, the cultures were passed through filter paper to remove the fungal mat, agar, and wood. The absorbance of the filtrate was measured at $416 \mathrm{~nm}$ for ABTS or $436 \mathrm{~nm}$ for guaiacol. One unit of enzyme activity was defined as an increase of one unit of absorbance per $1 \mathrm{~h}$ per flask. The absorbance due to fungal pigments in the filtrates, as determined in control filtrates which lacked substrate, were subtracted from the total absorbance to obtain the absorbance due to phenol oxidase activity.

Phenol oxidase activity was also assayed by a Bavendamm reaction in glucose and wood particle cultures. Guaiacol, used as the substrate, was dissolved in ethanol and added to the medium, which 
had been autoclaved and cooled to $50-60^{\circ} \mathrm{C}$. The final concentration of guaiacol in the medium was 0.02 and $0.2 \%(\mathrm{w} / \mathrm{v})$. The cultures were incubated at $28^{\circ} \mathrm{C}$ in the dark. The color of the cultures was checked by visual inspection from $d 7$ to $d 30$ after inoculation.

\section{Preparation of culture filtrates}

At each of the indicated times, the extracellular medium from the 10 glucose and Japanese beech wood particle cultures was acetone-precipitated (70\%, v/ v), as described previously (Tanaka et al., 1999a). The precipitate was passed through a Sephadex G-50 gel filtration column and the UV absorbances of the fractions were measured at $280 \mathrm{~nm}$. Three fractions were collected and designated as fractions I, II, and III, in the order of their elution from the column. The fractions were lyophilized, redissolved in $10 \mathrm{ml}$ of distilled water, and kept at $-80^{\circ} \mathrm{C}$ until use. The activities in each of the fractions were measured in duplicate.

\section{Ethylene generation from KTBA in culture filtrate fractions}

The reaction mixture $(1 \mathrm{ml})$ contained $300 \mu \mathrm{l}$ of $160 \mathrm{mM}$ acetate buffer ( $\mathrm{pH} 4.5), 300 \mu$ l of $10 \mathrm{mM}$ KTBA, and $100 \mu \mathrm{l}$ of sample. The reaction tube was purged through a rubber septum with $100 \%(\mathrm{~V} / \mathrm{V})$ $\mathrm{O}_{2}$ for $5 \mathrm{~min}$, followed by the addition of $10 \mathrm{mM}$ NADH $(300 \mu \mathrm{l})$. After $24 \mathrm{~h}$ at $30^{\circ} \mathrm{C}, 1 \mathrm{ml}$ of gas was removed from the head space and the ethylene concentration was measured directly by gas chromatography, as previously described (Enoki et al., 1989).

\section{Phenol oxidase activity in culture filtrate frac- tions}

Phenol oxidase activity was assayed spectrophotometrically, using ABTS or guaiacol as the substrate. With ABTS as the substrate, the reaction mixture $(1 \mathrm{ml})$ contained $100 \mathrm{mM}$ acetate buffer $(\mathrm{pH}$ 4.5), ABTS $(2 \mathrm{mM})$, and the sample $(100 \mu \mathrm{l})$. For peroxidase activity, the reaction was initiated by the addition of $\mathrm{H}_{2} \mathrm{O}_{2}$ to a final concentration of $200 \mu \mathrm{M}$. For manganese peroxidase ( $\mathrm{MnP})$ activity, the reaction mixture also contained $\mathrm{MnSO}_{4}(200 \mu \mathrm{M})$. The absorbance at $416 \mathrm{~nm}\left(A_{416}\right)$ was measured after $10 \mathrm{~min}$ at $30^{\circ} \mathrm{C}$. With guaiacol as the substrate, the reaction mixture $(1 \mathrm{ml})$ contained $100 \mathrm{mM}$ acetate buffer $(\mathrm{pH} 4.5)$, guaiacol $(400 \mu \mathrm{M})$, and the sample (150 $\mu \mathrm{l})$. For peroxidase activity, the reaction was initiated by the addition of $\mathrm{H}_{2} \mathrm{O}_{2}$ to a final concn of $200 \mu \mathrm{M}$. For $\mathrm{MnP}$ activity, the reaction mixture also contained $\mathrm{MnSO}_{4}(200 \mu \mathrm{M})$. The $A_{436}$ was measured after $24 \mathrm{~h}$ at $30^{\circ} \mathrm{C}$. Non-MnP peroxidase activity was calculated by subtracting the laccase activity measured in the absence of $\mathrm{H}_{2} \mathrm{O}_{2}$, from the total activity measured in the presence of $\mathrm{H}_{2} \mathrm{O}_{2}$. MnP activity was calculated by subtracting the total activity measured in the presence of $\mathrm{H}_{2} \mathrm{O}_{2}$ and the absence of $\mathrm{Mn}^{2+}$, from the total activity measured in the presence of $\mathrm{Mn}^{2+}$. One unit of enzyme activity was defined as an increase of one unit of absorbance per min (ABTS) or per $24 \mathrm{~h}$ (guaiacol) per culture.

\section{Preparation of the low-molecular-weight fraction}

Cultures were grown in $30 \mathrm{ml}$ Duncan's medium containing $0.25 \%(\mathrm{w} / \mathrm{v})$ glucose, Japanese beech wood particles $(2.4 \mathrm{~g})$, prepared as described above, and $0.5 \mathrm{~g}$ agar, in 300-ml Erlenmeyer flasks. After 63 $\mathrm{d}$ of incubation, the extracellular medium from $60 \mathrm{cul}$ tures was acetone-precipitated $(70 \%, v / v)$, as described previously (Tanaka et al., 1999a). Fraction III was obtained as described above, lyophilized, weighed, and redissolved in an appropriate amount of distilled water.

The protein content of the low-molecular-weight fraction was assayed by the method of Lowry et al. (1951) with bovine serum albumin as the standard. The neutral carbohydrate content was measured by the phenol-sulfuric acid method with glucose as the standard (Dubois et al., 1956). The ferrous content was measured with ferrozine, a colorimetric reagent that forms a stable magenta complex with $\mathrm{Fe}$ (II), by the procedure of Sørensen (1982). A 20-fold diluted sample $(1 \mathrm{ml})$ was reacted with $500 \mu \mathrm{l}$ of $0.1 \%$ ferrozine solution in $50 \mathrm{mM} \mathrm{N}$-2-hydroxyethylpiperazine- $N^{\prime}$-2-ethanesulfonic acid buffer $(\mathrm{pH} 7.0)$ at 28 ${ }^{\circ} \mathrm{C}$ for $24 \mathrm{~h}$. The absorbance was measured over the range of $700 \mathrm{~nm}$ to $400 \mathrm{~nm}$.

\section{RESULTS}

The one-electron oxidation activities, as determined by ethylene generation from KTBA, in intact glucose, wood particle, and wood meal cultures of Graphium sp. are shown in Fig. 1. The highest activity was observed in wood meal cultures after one wk of incubation. The activity in wood meal cultures remained high after 2 wk of incubation, then decreased rapidly, and was negligible after $6 \mathrm{wk}$. The activity in wood particle cultures also was highest after one wk of incubation. It then decreased, remaining at a constant level between 5 and 8 wk of incubation. The activity in glucose cultures was highest after wk 2, and then decreased until wk 4, fluctuating within a narrow range between 4 and $8 w k$ of incubation. The integral of the ethylene generation was $16.5 \times 10^{-8} \mathrm{~mol}$ for glucose cultures, $21.9 \times 10^{-8} \mathrm{~mol}$ for wood meal cultures, and $34.2 \times 10^{-8} \mathrm{~mol}$ for wood particle cultures. 


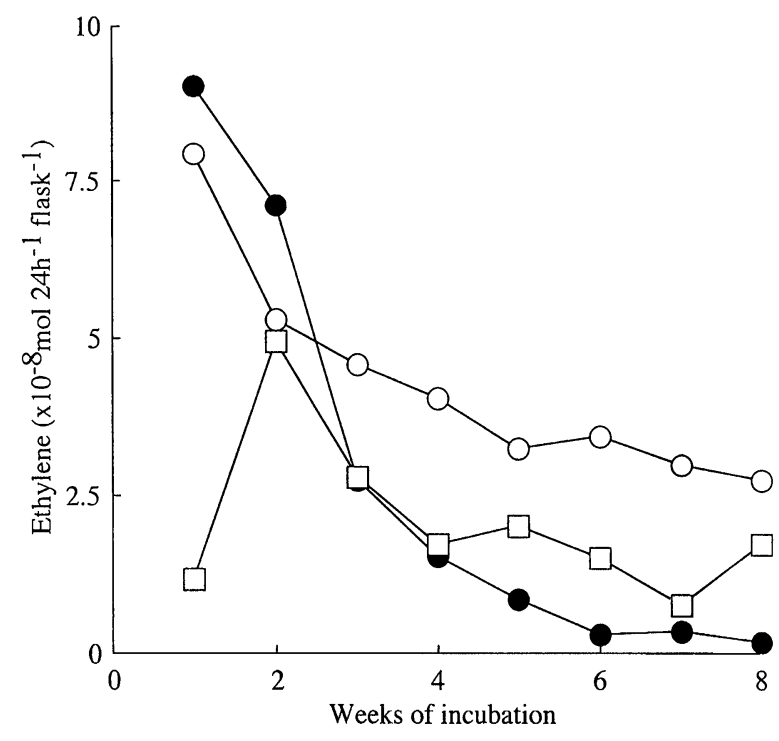

FIG. 1 . Ethylene generation from KTBA in cultures of Graphium sp. containing glucose $(\square)$, or Japanese beech wood particles $(\bigcirc)$ or wood meal (O). Assays were carried out as described in the text. Each value is the mean of the three replicate cultures.

The phenol oxidase activities in intact glucose, Japanese beech wood particle or wood meal, and Japanese cedar wood particle cultures of Graphium sp., with ABTS or guaiacol as the substrate, are shown in Fig. 2. With ABTS as the substrate, the activities in Japanese beech wood particle and wood meal cultures were high after one wk of incubation, peaking after wk 2 , and then gradually decreasing. With guaiacol as the substrate, the activity in Japanese beech wood particle cultures was much higher than that in wood meal cultures after wk 1. In Japanese cedar wood particle cultures, the time course of the activity was very similar to that in beech wood particle cultures with ABTS or guaiacol as the substrate. However the activity in the cedar particle cultures was much lower than that in the beech particle cultures. In both beech and cedar wood particle and beech wood meal cultures, the activity peaked after 2 wk and then declined. No phenol oxidase activity was detectable in glucose cultures with either substrate.

The phenol oxidase reaction by Graphium sp. in cultures containing glucose or Japanese beech wood particles is shown in Table 1. The Graphium sp. had no phenol oxidase activity at either concn of guaiacol in glucose cultures, but it had phenol oxidase activity at $0.2 \%(\mathrm{w} / \mathrm{v})$ of guaiacol in wood particle cultures.

The one-electron oxidation activities in culture filtrate fractions I and III from Japanese beech wood particle cultures, as measured by ethylene generation from KTBA in the presence of NADH under $\mathrm{O}_{2}$, are shown in Fig. 3. The highest activity was detected in fraction III from 10-d-old cultures. The activity in fraction III was higher than that in fraction I for cultures at each stage of incubation. The activity in fraction I from 16- and 63-d-old cultures was very low.

TABLE 1. Phenol oxidase reaction by Graphium sp. in cultures containing glucose or Japanese beech wood particles.

\begin{tabular}{lcc}
\hline \multirow{2}{*}{ Culture } & \multicolumn{2}{c}{ Concn of guaiacol $(\%, \mathrm{w} / \mathrm{v})$} \\
\cline { 2 - 3 } & 0.02 & 0.2 \\
\hline Glucose & $-^{a}$ & - \\
Wood particle & - & $+^{b}$ \\
\hline
\end{tabular}

${ }^{a}$ Negative reaction.

${ }^{b}$ Positive reaction.
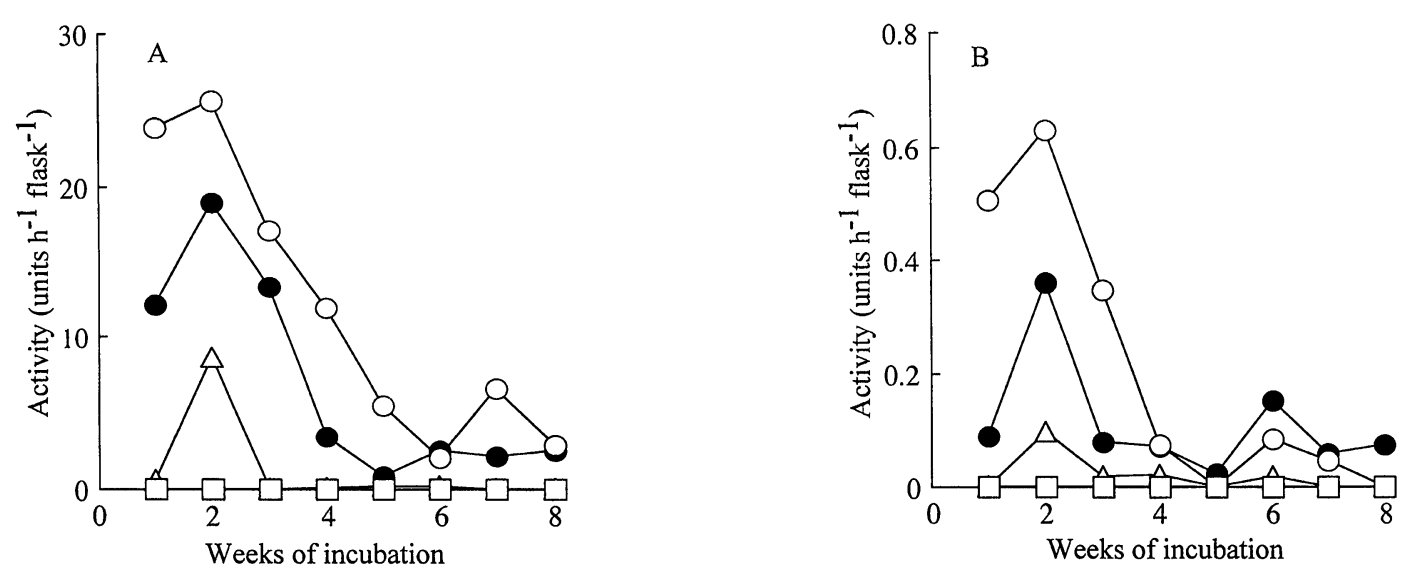

FIG. 2. Phenol oxidase activity, with ABTS (A) or guaiacol (B) as the substrate, in cultures of Graphium sp. containing glucose $(\square)$, Japanese beech wood particles $(\bigcirc)$ or wood meal $(\mathbf{O})$, and Japanese cedar wood particles $(\triangle)$. Assays were carried out as described in the text. Each value is the mean of the three replicate cultures. 


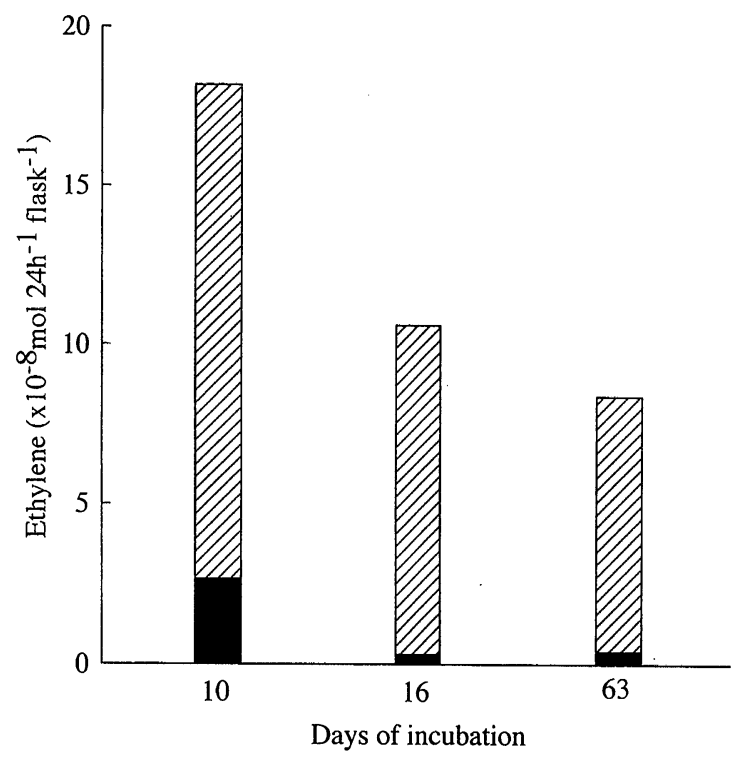

FIG. 3. Ethylene generation from KTBA with fractions I $(\square)$ and III ( $\square$ ) of the extracellular media from Japanese beech wood particle cultures of Graphium sp. Ethylene generation in the presence of $\mathrm{NADH}$, under $\mathrm{O}_{2}$, was assayed as described in the text.

The activities of laccase and non-MnP peroxidase in culture filtrate fraction I from glucose and Japanese beech wood particle cultures, measured using ABTS or guaiacol as the substrate, are shown in Fig. 4. With ABTS as the substrate, non-MnP peroxidase was the predominant phenol oxidase activity in fraction I from the extracellular media of glucose cultures after 10 and $16 \mathrm{~d}$ of incubation (Fig. 4A). With guaiacol as the substrate, activities were very low and negligible (Fig. $4 B$ ). With ABTS as the substrate, laccase activity in fraction I from the extracellular media of wood particle cultures was much higher than peroxidase activity (Fig. 4C) and much higher than the laccase activity in fraction I from glucose cultures (Figs. $4 \mathrm{~A}$ and $4 \mathrm{C}$ ). With guaiacol as the substrate, only laccase activity was detected (Fig. 4D). No MnP activity was detected in fraction I from either the glucose or wood particle cultures, with either substrate. Only extremely low levels of enzyme activity were detected in fractions II and III from both the glucose or wood particle cultures (data not shown).

Table 2 shows the dry weight, protein content, neutral carbohydrate content, $\mathrm{Fe}$ (II ) content, and the one-electron oxidation activity of the low-molecularweight fraction (fraction III) from the extracellular media of 60-d-old Japanese beech wood particle cultures. The ethylene generation from KTBA by the substance contained in fraction III under various conditions is shown in Table 3. A small amount of ethylene was generated from KTBA under $100 \%(\mathrm{v} / \mathrm{v})$
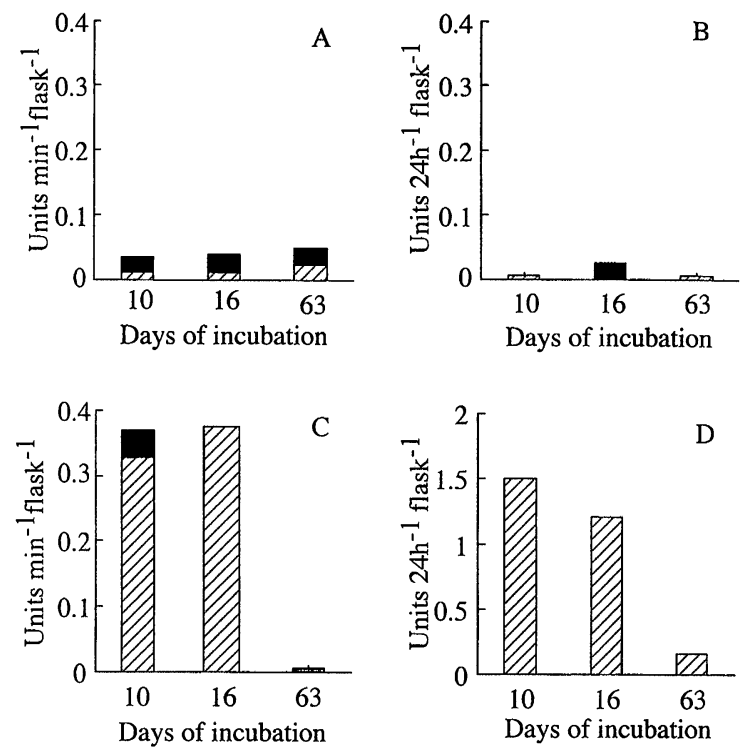

FIG. 4. Phenol oxidase activities in fraction $I$ of the extracellular media from glucose (A and B) and Japanese beech wood particle (C and D) cultures of Graphium sp. The activities of laccase $(\square)$ and non-MnP peroxidase (घ) were determined as described in the text, with ABTS ( $A$ and $C$ ) or guaiacol (B and D) as the substrate.

$\mathrm{O}_{2}$ and under $\mathrm{N}_{2}$. In the presence of $\mathrm{H}_{2} \mathrm{O}_{2}$, some ethylene was generated under anaerobic conditions. In the presence of $\mathrm{NADH}$ under $\mathrm{O}_{2}$, ethylene generation from KTBA was 30-fold higher than in the absence of $\mathrm{NADH}$. The presence of catalase or the hydroxyl radical scavenger, $N, N^{\prime}$-dimethyl-4-nitrosoaniline, greatly reduced ethylene generation from KTBA in the presence of $\mathrm{NADH}$ (Table 3 ).

\section{DISCUSSION}

Recently, we demonstrated that one-electron oxidation activity and phenol oxidase activity of four soft-rot deuteromycetes, including Graphium sp. M-1-9, are

TABLE 2. Analysis of the low-molecular-weight fraction (Fraction III) from the extracellular media of 63-d-old Japanese beech wood particle cultures of Graphium sp.

\begin{tabular}{ll}
\hline Item & Value \\
\hline Dry wt. (mg) & 84.2 \\
Protein (mg) & $10.5(12.5)^{a}$ \\
Neutral carbohydrate $(\mathrm{mg})$ & $47.2(56.0)$ \\
Fe $($ II $)(\mu \mathrm{g})$ & $5.1(0.01)$ \\
Ethylene generation (nmol mg dry $\left.\mathrm{wt.}^{-1} \mathrm{~h}^{-1}\right)$ & 0.05 \\
\hline
\end{tabular}

${ }^{a}$ Percent of mg dry wt. 
TABLE 3. Effect of $\mathrm{O}_{2}$ and $\mathrm{N}_{2}$ atmospheres, and of $\mathrm{H}_{2} \mathrm{O}_{2}$, electron donors, and a hydroxyl radical scavenger on the generation of ethylene from KTBA by an extracellular one-electron oxidant isolated from Graphium sp.

\begin{tabular}{lcrr}
\hline \multirow{2}{*}{ Addition to reaction mixture } & & \multicolumn{2}{c}{ Ethylene generation } \\
\cline { 3 - 4 } & Atmosphere & $\mathrm{nmol} \mathrm{h}^{-1}$ & $\%^{b}$ \\
\hline None & & 0.5 & 3 \\
None & $\mathrm{O}_{2}$ & 0.3 & 2 \\
$\mathrm{H}_{2} \mathrm{O}_{2}\left(3 \times 10^{-6} \mathrm{~mol}\right)$ & $\mathrm{N}_{2}$ & 2.6 & 18 \\
$\mathrm{NADH}\left(3 \times 10^{-6} \mathrm{~mol}\right)$ & $\mathrm{O}_{2}$ & 14.9 & 100 \\
$\mathrm{NADH}\left(3 \times 10^{-6} \mathrm{~mol}\right)$, catalase $^{c}(0.3 \mathrm{mg})$ & $\mathrm{O}_{2}$ & 4.4 & 29 \\
$\mathrm{NADH}\left(3 \times 10^{-6} \mathrm{~mol}\right), \mathrm{DMNA}^{d}\left(6 \times 10^{-6} \mathrm{~mol}\right)$ & $\mathrm{O}_{2}$ & 0.9 & 6 \\
\hline
\end{tabular}

${ }^{a}$ Reaction mixtures ( $2 \mathrm{ml}$ in $7-\mathrm{ml}$ test tube) contained $1 \mathrm{mg}$ of the low-molecular-weight fraction, prepared as described in the text from 63-d-old wood particle cultures, KTBA $\left(3 \times 10^{-6} \mathrm{~mol}\right)$, and acetate bufer $(\mathrm{pH} 4.5,160 \mathrm{mM})$. The tubes were purged with $100 \% \mathrm{O}_{2}$ for min or $100 \% \mathrm{~N}_{2}$ for $30 \mathrm{~min}$.

${ }^{\circ}$ Percent of ethylene generation with $\mathrm{NADH}$.

${ }^{\circ} 41,000$ Units/mg.

${ }^{d} N, N$-Dimethyl-4-nitrosoaniline.

stimulated by the presence of Japanese beech wood (Tanaka et al., 1999c). Fusarium sp. and Trichoderma sp., which are strong cellulolytic fungi but which cannot degrade wood, have a lower oneelectron oxidation activity in wood particle cultures than in glucose cultures. No phenol oxidase activity is detected in these two fungi when guaiacol is used as the substrate. Therefore, we have suggested that oneelectron oxidation activity and phenol oxidase activity play important roles in wood degradation by soft-rot fungi, as they do in wood degradation by white-rot fungi (Tanaka et al., 1999a and 1999b). However, since ethylene is generated from KTBA by oneelectron oxidants such as the hydroxyl radical, peroxidase $/ \mathrm{H}_{2} \mathrm{O}_{2}$ systems, and ceric ammonium sulfate (Enoki et al., 1989), it is not clear what produces the one-electron oxidation activity in these soft-rot fungi. In order to better understand the mechanism of wood decay by the soft-rot fungus Graphium sp., we have attempted to isolate and identify its phenol oxidases and determine the agent that is responsible for one-electron oxidation in wood cultures of this fungus.

No phenol oxidase activity was detected in intact glucose cultures of Graphium sp. (Fig. 2), although peroxidase activity was detectable in fraction I of the extracellular media from glucose cultures (Fig. 4). Although under natural conditions, soft-rot is detected in softwood poles in the ground-line zones (Eaton and Hale, 1993), under laboratory conditions soft-rot fungi cannot degrade softwood as rapidly or extensively as it degrades hardwood (Duncan, 1960; Eslyn et al., 1975; Nilsson et al., 1989; Savory, 1954), and Graphium sp. cannot degrade Japanese cedar efficiently (data not shown). When Graphium sp. was grown with particles of Japanese cedar instead of
Japanese beech, phenol oxidase activity was much lower, with either ABTS or guaiacol as the substrate. No phenol oxidase activity was detected in cultures containing $0.25 \%$ glucose as the sole carbon source (data not shown). These results indicate that Graphium sp. exhibits phenol oxidase activity only in wood-degrading cultures. Laccase activity was much higher in fraction I of the extracellular media from wood cultures as compared with glucose cultures. With guaiacol as the substrate, laccase activity was the only phenol oxidase activity detected in wood cultures (Fig. 4). Thus, most of the phenol oxidase activity in wood cultures of Graphium sp. appears to derive from laccase.

Most white-rot fungi exhibit a positive Bavendamm reaction for phenol oxidase activity in both glucose and wood-containing cultures when guaiacol is added to a final concentration of $0.02 \%$ to agar medium (Käärik, 1965; Tanaka et al., 1996). Under these conditions Graphium sp. does not exhibit a positive Bavendamm reaction. However at a final guaiacol concentration of $0.2 \%$, wood-containing cultures of Graphium sp. in fact exhibited a positive reaction (Table 1). This result may reflect a difference in the diffusability of phenol oxidases from white-rot and soft-rot fungi.

The maximum level of ethylene generation in intact cultures of Graphium sp. (Fig. 1) is about 3\% of that in cultures of the brown-rot fungus Tyromyces palustris (Hirano et al., 1997) and about $5 \%$ of that in cultures of the white-rot fungi Phanerochaete chrysosporium (Tanaka et al., 1999a) and Trametes versicolor (Tanaka et al., 1999b). However, the ethylene generated in Japanese beech wood particle cultures of Graphium sp. remained at a fairly constant level in the later stages of incubation (Fig. 1), and 
ethylene generation was much higher in fraction $\mathrm{II}$ of the extracellular media than in fraction I (Fig. 3). Fraction III contained a low-molecular-weight substance consisting of peptides, carbohydrates, and $\mathrm{Fe}$ (II) (Table 2). This low-molecular-weight substance was very similar to that obtained from brownrot and white-rot fungi (Hirano et al., 1997; Tanaka et al., 1991 and 1996).

Ethylene generation from KTBA by fraction III was inhibited by the addition of catalase or a hydroxyl radical scavenger (Table 3 ). This suggests that the lowmolecular-weight fraction, isolated from the extracellular media of wood cultures of Graphium sp., catalyzes a redox reaction between an electron donor, such as $\mathrm{NADH}$, and $\mathrm{O}_{2}$ to produce hydroxyl radical via $\mathrm{H}_{2} \mathrm{O}_{2}$, as previously described for brown-rot and white-rot fungi (Hirano et al., 1997; Tanaka et al., 1991 and 1996). Although laccase cannot modify or degrade non-phenolic lignins, the main component of wood cell wall lignin, if the hydroxyl radical produces terminal phenolics on the polymer, laccase then can degrade lignin in wood. The fairly constant level of one-electron oxidation activity in intact wood cultures and in fraction III from the extracellular media of wood cultures (Figs. 1 and 3 ) indicates that the hydroxyl radical is produced throughout the course of incubation of Graphium sp. In this study, the low-molecularweight fraction (fraction $\mathrm{III}$ ) was prepared from the extracellular medium of 63 -d-old cultures in order to maximize the amount of acetone-precipitable material. However, since the one-electron oxidation activity in fraction III was highest on d 10, future experiments will utilize 10-d-old cultures.

The addition of lignocellulosic substrates to cultures of Thermoascus aurantiacus, a thermophilic fungus, induces phenol oxidases. The type of phenol oxidase activity depends on the type of lignocellulosic substrate and the highest laccase activity is obtained with sawdust (Machuca and Durán, 1993). Recently, it has been reported that hydroxyl radicals and laccase are produced in cultures of the soft-rot fungus Fusarium proliferatum, and that the generation of the hydroxyl radical, but not laccase activity, is related to lignin mineralization by the cultures (Regalado et al., 1999). Likewise with Graphium sp., one-electron oxidation activity and laccase activity are stimulated by the presence of wood particles or wood meal of Japanese beech (Figs. 1 and 2). The integrals of both activities are higher in wood particle cultures than in wood meal cultures. The cellulose in wood meal is probably more exposed. Therefore, less lignin degradation is required for the cellulolytic enzymes to access the cellulose, resulting in lower one-electron oxidation and laccase activities.
Because of the vast anatomical, microstructural, and chemical variabilities among hardwoods, it is difficult to perform the efficient application and fixation of wood preservatives (Ryan and Drysdale, 1988; Srinivasan et al., 1998). In contrast to white-rot and brown-rot fungi, whose hyphae develop inside the cell lumen, soft-rot fungi grow preferentially within the $S_{2}$ layer of the cell wall, making effective treatment difficult. Fewer hydroxyl radicals and low diffusability of phenol oxidases of Graphium sp. may cause localized decay around hyphae. Transverse sections of copperchromium-arsenic (CCA) preservative-treated Eucalyptus deglupta infected with the soft-rot fungus Lecythophora (Phialophora) mutabilis reveals heavy granular deposits of the preservative on cell wall lumen surfaces, but only low levels of CCA in the $S_{2}$ layers of the cell walls that are vulnerable to soft-rot cavity attack (Eaton and Hale, 1993). Once soft-rot fungi that are present in the cell lumina are able to breach the CCA deposits on the cell wall surface, hyphae can grow within the colonized cell walls and into adjacent cell walls without re-encountering the thick CCA deposits. Thus, protection from soft-rot decay requires highly-permeable preservatives or treatments which can be efficiently applied and fixed to prevent and control fungal penetration into cell wall lumina.

In conclusion, one-electron oxidation activity, primarily due to hydroxyl radical, and at least one phenol oxidase activity are involved in wood degradation by the soft-rot deuteromycete Graphium sp. The laccase from this fungus is being purified in our laboratory and compared with laccases from white-rot fungi. This work should lead to more effective preventative treatments against soft-rot decay.

\section{REFERENCES}

Bailey, P. J., Liese, W., and Rösch, R. (1968) Some aspects of cellulose degradation in lignified cell walls. In Biodeterioration of Materials (Walters, A. H., and Elphick, J. J., eds.), pp. 546-557, Elsevier, Amsterdam.

Chirat, C., and Lachenal, D. (1997) Effect of hydroxyl radicals on cellulose and pulp and their occurrence during ozone bleaching. Holzforschung, 51, 147-154.

Dubois, M., Gilles, K. A., Hamilton, J. K., Rebers, P. A., and Smith, F. (1956) Colorimetric method for determination of sugars and related substances. Anal. Chem., 28, 350-356.

Duncan, C. G. (1960) Wood-attacking capacities and physiology of soft-rot fungi. U. S. Forest Products Lab. Rep., 2173, 1-28.

Eaton, R. A., and Hale, M. D. C. (1993) Presevative chemicals. In Wood Decay, Pests and Protection, pp. 344-372, Chapman \& Hall, London.

Enoki, A., Tanaka, H., and Fuse, G. (1988) Degradation of lignin-related compounds, pure cellulose, and wood com- 
ponents by white-rot and brown-rot fungi. Holzforschung, 42, 85-93.

Enoki, A., Tanaka, H., and Fuse, G. (1989) Relationship between degradation of wood and production of $\mathrm{H}_{2} \mathrm{O}_{2}$ producing or one-electron oxidases by brown-rot fungi. Wood Sci. Technol., 23, 1-12.

Enoki, A., Itakura, S., and Tanaka, H. (1997) The involvement of extracellular substances for reducing molecular oxygen to hydroxyl radical and ferric iron to ferrous iron in wood degradation by wood decay fungi. J. Biotechnol., 53, 265-272.

Eslyn, W. E., Kirk, T. K., and Effland, M. J. (1975) Changes in the chemical composition of wood caused by six softrot fungi. Phytopathology, 65, 473-476.

Gierer, J., Yang, E., and Reitberger, T. (1992) The reactions of hydroxyl radicals with aromatic rings in lignins, studied with cresol and 4-methylveratrol. Holzforschung, 46, 495504.

Highley, T. L. (1973) Influence of carbon source on cellulase activity of white-rot and brown-rot fungi. Wood Fiber, 5, 50-58.

Highley, T. L. (1987) Changes in chemical components of hardwood and softwood by brown-rot fungi. Mater. Org., 22, 39-45.

Hirano, T., Tanaka, H., and Enoki, A. (1997) Relationship between production of hydroxyl radicals and degradation of wood by the brown-rot fungus, Tyromyces palustris. Holzforschung, 51, 389-395.

Itakura, S., Hirano, T., Tanaka, H., and Enoki, A. (1994) Relationship between degradation of wood, cellulose or lignin-related compounds and production of hydroxyl radical or accumulation of oxalic acid in cultures of brown-rot fungi. Int. Res. Group Wood Preserv., IRG Secretariat, Stockholm, Doc. No. IRG/WP/94-10062.

Käärik, A. (1965) The identification of the mycelia of wooddecay fungi by their oxidation reactions with phenolic compounds. Stud. For. Suec., no. 31.

Kirk, T. K., Ibach, R., Mozuch, M. D., Conner, A. H., and Highley, T. L. (1991) Characteristics of cotton cellulose depolymerized by a brown-rot fungus, by acid, or by chemical oxidants. Holzforschung, 45, 239-244.

Koenigs, J. W. (1974) Hydrogen peroxide and iron: A proposed system for decomposition of wood by brown-rot basidiomycetes. Wood Fiber, 6, 66-80.

Kumagai, H., and Tsunoda, K. (1999) Discoloration of imported North American woods by sap-stain fungus, Graphium sp. and its prevention (in Japanese). Mokuzai Gakkaishi, 45, 164-170.

Lowry, O. H., Rosebrough, N., Farr, A. L., and Randall, R. J. (1951) Protein measurement with the Folin phenol reagent. J. Biol. Chem., 193, 265-275.

Machuca, A., and Durán, N. (1993) Phenol oxidases production and wood degradation by thermophilic fungus Thermoascus aurantiacus. Appl. Biochem. Biotechnol. 43, $37-44$.

Nilsson, T., Daniel, G., Kirk, T. K., and Obst, J. R. (1989) Chemistry and microscopy of wood decay by some higher ascomycetes. Holzforschung, 43, 11-18.

Regalado, V., Rodríguez, A., Perestelo, F., Carnicero, A., Fuente, G. de la, and Falcón, M. A. (1997) Lignin degradation and modification by the soil-inhabiting fungus Fusarium proliferatum. Appl. Environ. Microbiol., 63, 3716-
3718.

Ryan, K. G., and Drysdale, J. A. (1988) X-ray analysis of copper chromium and arsenic within the cell walls of treated hardwoods-new evidence against the microdistribution theory. J. Inst. Wood Sci., 11, 108-113.

Savory, J. G. (1954) Breakdown of timber by ascomycetes and fungi imperfecti. Ann. Appl. Biol., 41, 336-347.

Sørensen, J. (1982) Reduction of ferric iron in anaerobic, marine sediment and interaction with reduction of nitrate and sulfate. Appl. Environ. Microbiol., 43, 319-324.

Srinivasan, U., Ung, T., and Cooper, P. A. (1998) Susceptibility of CCA treated North American hardwoods to Chaetomium globosum decay. Int. Res. Group Wood Preserv., IRG Secretariat, Stockholm, Doc. No. IRG/WP/ 98-10278.

Tanaka, H., and Fuse, G. (1981) Succession and interaction of microorganisms participating in wood decay. II . Species and frequency of isolation fungi from a stake test under the floor of a house (in Japanese). Mokuzai Gakkaishi, 27, 893-901.

Tanaka, H., and Fuse, G. (1983) Succession and interaction of microorganisms participating in wood decay. III . Species and succession of fungi from a stake test under the floor of a house. Mokuzai Gakkaishi, 29, 382-395.

Tanaka, H., Enoki, A., and Fuse, G. (1985) Succession and interaction of microorganisms participating in wood decay. IV. Degradation ability of fungi isolated from a stake test under the floor of a house (in Japanese). Mokuzai Gakkaishi, 31, 935-945.

Tanaka, H., Enoki, A., and Fuse, G. (1986) Correlation between ethylene production from $\alpha$-oxo- $\gamma$-methylthiobu- $t$ yric acid and degradation of lignin dimeric model compounds by wood-inhabiting fungi. Mokuzai Gakkaishi, 32 , 125-135.

Tanaka, H., Fuse, G., and Enoki. A. (1991) An extracellular $\mathrm{H}_{2} \mathrm{O}_{2}$-producing and $\mathrm{H}_{2} \mathrm{O}_{2}$-reducing glycopeptide preparation from the lignin-degrading white-rot fungus, Irpex lacteus. Mokuzai Gakkaishi, 37, 986-988.

Tanaka, H., Fuse, G., and Enoki. A. (1992) Soft-rot of wood caused by three microfungi grown on four media. Mater. Org., 27, 157-170.

Tanaka, H., Itakura, S., Hirano, T., and Enoki, A. (1996) An extracellular substance from the white-rot basidiomycete Phanerochaete chrysosporium for reducing molecular oxygen and ferric iron. Holzforschung, 50, 541-548.

Tanaka, H., Itakura, S., and Enoki, A. (1999a) Hydroxyl radical generation by an extracellular low-molecular-weight substance and phenol oxidase activity during wood degradation by the white-rot basidiomycete Phanerochaete chrysosporium. Holzforschung, 53, 21-28.

Tanaka, H., Itakura, S., and Enoki, A. (1999b) Hydroxyl radical generation by an extracellular low-molecular-weight substance and phenol oxidase activity during wood degradation by the white-rot basidiomycete Trametes versicolor. J. Biotechnol., 75, 57-70.

Tanaka, H., Itakura, S., and Enoki, A. (1999c) Phenol oxidase activity and one-electron oxidation activity in wood degradation by soft-rot deuteromycetes. Holzforschung, in press.

Zabel, R. A., and Morrell, J. J. (1992) General features, recognition, and anatomical aspects of wood decay. In Wood Microbiology, pp. 168-194, Academic Press, San Diego. 